\section{Absence of anisakis nematodes in smoked farmed Atlantic salmon (Salmo salar) products on sale in European countries}

\author{
Miguel Ángel Pardo González, ${ }^{1}$ \\ Giulia Cavazza, ${ }^{2}$ Andrea Gustinelli, ${ }^{2}$ \\ Monica Caffara, ${ }^{2}$ \\ Marialetizia Fioravanti ${ }^{2}$
}

${ }^{1}$ Food Research Division, AZTI Parque

Tecnológico de Bizkaia, Astondo Bidea,

Bizkaia, Spain; ${ }^{2}$ Department of

Veterinary Medical Sciences, Alma

Mater Studiorum, University of

Bologna, Ozzano Emilia (BO), Italy

\begin{abstract}
The increase of global demand of aquaculture products as compensation for the lowering of fishery sustainability has shown a parallel awareness by the consumers on the importance of the safety and quality of fish products. Among these, salmon industry has reached a leading position demonstrating the negligible risk of presence of zoonotic helminths such as anisakis nematodes in farmed salmon. Despite the massive production of data in literature on parasitological surveys carried out on fresh salmon, no data are published on processed farmed salmon such as smoked products. In 2016, 270 slices of smoked farmed Atlantic salmon (Salmo salar) and 13 smoked slices from wild sockeye salmon (Oncorhynchus nerka) have been analyzed by visual inspection and UV-press method searching for the presence of anisakid nematodes. No parasites were detected in samples from farmed Atlantic salmon, while 10 out of 13 from wild salmon were positive for Anisakis simplex s.s. larvae. This first survey on the possible presence of anisakid nematodes in processed smoked salmon confirms that this risk in farmed Atlantic salmon products has to be considered negligible.
\end{abstract}

\section{Introduction}

There is an extensive range of helminthic parasites of fish, but only a moderate number of species are capable of producing foodborne diseases in humans (Adams, Murrell, and Cross, 1997; Chai, Murrell, and Lymbery, 2005). These diseases are either caused by an infection following ingestion of viable larval stages of fish parasites, or as an allergic reaction against parasite antigens which occurs, so far, for nematodes of the family Anisakidae. Anisakis simplex (s.l.) is most frequently associated with human disease, denominated Anisakiasis, followed by Pseudoterranova decipiens (s.l.) (Buchmann and Mehrdana, 2016). In fact, A. simplex is the second most predominant biological hazard notified in seafood products, constituting $19.5 \%$ of the reported hazards (Kleter, Prandini, Filippi, and Marvin, 2009) and in recent years a blip is observed in the notifications for this nematode, with more than 700 alerts since 2010 according to the EU Rapid Alert System for Food and Feed - RASFF (https://ec. europa.eu/food/safety/rasff_en) and several fish species involved.

Among these, Atlantic salmon (Salmo salar) is susceptible of being infected by anisakid nematodes in natural environments (Noguera et al., 2009; Wootten, Yoon, and Bron, 2010), although several studies carried out in Norway and Scotland did not show the presence of zoonotic anisakids in farmed Atlantic salmon (Angot, 1993; Deardorff and Kent, 1989; Lunestad, 2003; Wootten, Yoon, and Bron, 2009). This evidence drove the European Food Safety Authority (2010) to state that, for farmed Atlantic salmon, the risk of infection with anisakids is negligible and the European Commission to modify the Annex III of Regulation (EC) $853 / 2004$ by issuing the Regulation (EU) 1276/2011, allowing to business operators the exemption of the freezing treatment for farmed Atlantic salmon products intended to be consumed raw or undercooked, if the indications reported in the Regulation are fully respected. Moreover a qualitative risk assessment analysis in Atlantic salmon has concluded the very low risk associated to commercialization of farmed salmon with viable anisakids (Crotta, Ferrari, and Guitian, 2016).

Despite the reassuring evidences emerging from these data and although, so far, no nematodes were found in farmed harvest quality salmon intended for human consumption, more recently the presence of anisakid parasites has been reported in runts of Atlantic salmon farmed in Norway (Levsen and Maage, 2016; Mo et al., 2014), questioning somehow the exemption for farmed Atlantic salmon from the freezing requirement included in the current EU legislation, with potential negative repercussion on the salmon products market.

Atlantic salmon (Salmo salar) is by quantity the largest species of salmonids produced worldwide (FAO, 2018). In 2017, the total supply of Atlantic salmon was 2.248 million tons GWE (gutted weight equivalent) and most commercially avail-
Correspondence: Miguel Ángel Pardo González, Food Research Division, AZTI Parque Tecnológico de Bizkaia, Astondo Bidea, Bizkaia, Spain.

Tel.: +34 94657 4000; Fax: +34 946572555 E-mail: mpardo@azti.es

Key words: Farmed Atlantic salmon; Salmo salar; Anisakis risk; smoked products.

Acknowledgements: Our study was carried out within the framework of ParaFishControl (n ${ }^{\circ}$ 634429), an EU H2020-funded project that aims at increasing the sustainability and competitiveness of the European aquaculture industry through control and mitigation of the most harmful parasites affecting the main European farmed fish species

Conflict of interest: The authors declare no potential conflict of interest.

Contributions: The authors contributed equally.

Received for publication: 10 October 2019. Accepted for publication: 12 June 2020.

This work is licensed under a Creative Commons Attribution-NonCommercial 4.0 International License (CC BY-NC 4.0).

\section{(C) Copyright: the Author(s), 2020}

Licensee PAGEPress, Italy

Italian Journal of Food Safety 2020; 9:8615

doi:10.4081/ijfs.2020.8615

able is farmed. Atlantic salmon is a versatile product that can be used for a variety of primary and processed secondary products such as fillets, slices and smoked, respectively (MarineHarvest, 2018). Sliced fillets are the largest category of value added salmon products in terms of volume, with the $47 \%$, followed by smoked salmon at 28\% (Denstad, Lillevand, and Ulsund, 2015). The European market for smoked salmon is estimated to 185,000 tonnes in 2017 and the ten largest producers of smoked salmon in Europe are estimated to have a joint market share of more $60 \%$ (MarineHarvest, 2018). European smoked salmon production is part of a very complex food chain that can increase food safety risks after fillets manipulation from different origins. Food chain is longer and more complex than ever before and a failure of traceability from the farming through processing, transport, trade and catering can have significant food safety implications. However, despite of the commercial importance of this processed product, as far as we know, there are no surveys evaluating the possible presence of Anisakidae larvae in commercial smoked Atlantic salmon products. 
The present investigation aims to assess a food risk analysis of the presence of anisakid parasites in packaged slices of smoked salmon commercialized in Europe, carrying out a representative survey on this fish product and taking into consideration the main smoked salmon suppliers in supermarkets located in three of the main European markets: Italy, Spain and France.

\section{Materials and Methods}

\section{Smoked salmon sampling}

The sampling was carried out temporarily (spring "P1" and autumn "P2") in local supermarkets in Basque region (Spain and France) and Italy during 2016 (Table 1). Since the expected prevalence of anisakid larvae should have been low, we established a sample size of 270 salmon slices between $100-200 \mathrm{~g}$, and the confidence level was set at $90 \%$ with an acceptable margin of error set at 5\%. Sub samples size was split per suppliers, reflecting their salmon commercial production volume in 2015 in the countries under study.

In addition, 13 samples of smoked slices of wild sockeye salmon (Oncorhynchus nerka), 2 from supermarkets in Spain and 11 from Italy, were also collected to compare smoked farmed $v S$ wild salmon products, since from literature wild salmon has very high prevalence values for Anisakis larvae (Deardorff and Kent, 1989; Karl, Baumann, Ostermeyer, Kuhn, and Klimpel, 2011).

The significance of differences between prevalence values of samples from farmed and wild salmon was calculated using Chisquared test. Significant P-value was considered $<0.01$.

\section{Parasite inspection procedure}

Immediately after sampling, all smoked salmon samples were placed in a cooler and transported to the laboratory where they were kept refrigerated and then processed. Each smoked portion included in the package was placed into a clear plastic bag ensuring there was enough space in the bag for compression. Using a UV-press method, samples were squeezed until they were approximately $1-2 \mathrm{~mm}$ thick in a hydraulic pressing device at 7-8 bar. Then slices were frozen at $-20{ }^{\circ} \mathrm{C}$ for at least 48 hours and examined under ultraviolet light $(365 \mathrm{~nm})$, where anisakid larvae, if present, would appear as a fluorescent body (Karl and Leinemann, 1993). All the samples were previously subjected to visual inspection by candling, as provided by the current regulatory framework (EC Regulation 2074/2005).

All anisakid larvae detected and isolated in the samples examined were studied morphologically according to Berland
(1961), dissecting the anterior and posterior part of each larva and clarifying it with Amman's Lactophenol, while the middle part was subjected to molecular identification after DNA extraction from each parasite. In the Spanish control laboratory, parasite was mixed with $300 \mu \mathrm{L}$ extraction buffer (1\% (w/v) SDS, $150 \mathrm{mM} \mathrm{NaCl}, 2 \mathrm{mM}$ EDTA, Tris-HCl pH 8.0) supplemented with $40 \mu \mathrm{L} 5 \mathrm{M}$ guanidine thiocyanate, 50 $\mu \mathrm{L}$ proteinase $\mathrm{K}(600 \mathrm{UmL}-1)$ and subsequently incubated at $56^{\circ} \mathrm{C}( \pm 5)$ overnight. After centrifugation for $5 \mathrm{~min}$ at $16,000 \mathrm{~g}$ the supernatant was purified using Wizard Genomic DNA Purification Kit (Promega). DNA quality and quantity were determined with a NanoDrop Spectrophotometer (Thermo Fisher Scientific Inc.). PCR amplification of mitochondrial cytochrome c oxidase II gene (COII) was carried out with the primers CYTCII-F and CYTCII-R following the protocol previously described (López and Pardo, 2010). The reaction was started by adding 1 unit/reaction Taq DNA polymerase (Life Technologies) and amplification reactions were developed in a Mastercycler Personal (Eppendorf) for 40 cycles with an annealing temperature of $58^{\circ}$ C. The sequencing of amplified fragments was carried out directly on the purified fragments with a 3700 DNA Analyzer ABI PRISM, using the ABI Prism BigDye Terminator Cycle Sequencing Ready Reaction Kit, version 3.0 (Applied

Table 1. Summary of the sampling carried out temporarily in local supermarkets during 2016.

\begin{tabular}{|c|c|c|c|c|c|c|c|}
\hline \multirow[t]{2}{*}{ Producer } & \multirow{2}{*}{$\begin{array}{l}\text { Estimated } \\
\text { GWE } \\
\text { tonnes }\end{array}$} & \multirow{2}{*}{$\begin{array}{c}\text { Estimate } \\
\text { annual } \\
\text { production (\%) }\end{array}$} & \multirow[t]{2}{*}{ Supermarket } & \multicolumn{3}{|c|}{ Number of samples } & \multirow[t]{2}{*}{ Country } \\
\hline & & & & Total & P1 & P2 & \\
\hline Marine Harvest - Morpol & 80,000 & 30 & ESSELUNGA & 51 & 14 & 37 & Italy \\
\hline Marine Harvest - Harvest & 80,000 & 30 & ESSELUNGA & 51 & 14 & 37 & Italy \\
\hline Marine Harvest - Freihofer (Laschinger Morpol) & 80,000 & 30 & Aldi & 8 & 4 & 4 & Spain \\
\hline Labeyrie - Labeyrie & 30,000 & 10 & $\mathrm{COOP}$ & 43 & 43 & 0 & Italy \\
\hline Labeyrie - Delpierre & 30,000 & 10 & Intermarché & 13 & 7 & 6 & France \\
\hline Ubago & 15,000 & 5 & Mercadona & 20 & 9 & 4 & Spain \\
\hline Norvelita & 15,000 & 5 & COOP & 15 & 0 & 15 & Italy \\
\hline Suempol (Norfisk Berlin) & 15,000 & 5 & Lidl & 13 & 7 & 6 & Spain \\
\hline Mer Alliance & 15,000 & 5 & Carrefour & 14 & 7 & 7 & France \\
\hline Delpeyrat & 15,000 & 5 & Carrefour & 14 & 7 & 7 & France \\
\hline Xantelmar & 7,500 & 3 & El Corte Inglés & 9 & 5 & 4 & Spain \\
\hline Starlaks & 7,500 & 3 & ESSELUNGA & 14 & 0 & 14 & Italy \\
\hline Salmon Sur & 7,500 & 3 & Eroski & 8 & 4 & 4 & Spain \\
\hline La Balinesa & 7,500 & 3 & El Corte Inglés & 8 & 4 & 4 & Spain \\
\hline Koral & 7,500 & 3 & Eroski & 8 & 4 & 4 & Spain \\
\hline Intermarché (Odyssee) & 7,500 & 3 & Intermarché & 8 & 4 & 4 & France \\
\hline Fjord & 7,500 & 3 & $\mathrm{COOP}$ & 12 & 12 & 0 & Italy \\
\hline Ahumados Dominguez & 7,500 & 3 & Opencor & 8 & 4 & 4 & Spain \\
\hline El Duende & $<5,000$ & 1 & El Corte Inglés & 4 & 2 & 2 & Spain \\
\hline
\end{tabular}


Biosystems). In the Italian control laboratory the identification of the larvae has been carried out by PCR-RFLP of the ITS rDNA region (D'Amelio et al., 1999; Kijewska, Rokicki, Sitko, and Wegrzyn, 2002; Zhu et al., 2007) .

No anisakis larvae were present in any of the smoked farmed Atlantic salmon samples commercialized and intended for human consumption. Conversely, 10 (76.9\%) out of 13 smoked slices of wild sockeye salmons were positive for Anisakis larvae.

A significant difference $(p<0.001)$ has been evidenced between farmed and wild salmon.

Twenty-eight parasites (including also fragments referable to a single parasite) were found under UV light examination (Figure 1); of these, two had not been detected by candling. Once those parasites were isolated from the samples the morphological study allowed to identify all the larvae as Anisakis sp. type 1 (sensu Berland, 1961). Molecular identification identified the nematodes as A. simplex (s.s.).

\section{Discussion}

It is generally assumed that farmed fish products have a very low or null prevalence

\section{Results}

of zoonotic parasites, due to the low likelihood to prey intermediate or paratenic hosts from the natural food chain, necessary for parasite transmission to the cultured fish stocks, fostered by the high level of domestication of farmed fish that are used to feed exclusively on extruded commercial pellets, in an optimized farm management (Crotta et al., 2016; EFSA, 2010). Since no parasites were found in the 270 smoked Atlantic salmon samples analyzed in our study, these results are consistent with those previously carried out and evidencing the absence of parasitic nematodes in Norwegian farmed harvest quality Atlantic salmon (Levsen and Maage, 2016) and in Scottish farmed Atlantic salmon (Wootten et al., 2010). The survey is enough representative of the commercialization of this very appreciated seafood product in Europe, including the main European producers and countries where the consumption of smoked salmon is high. Moreover, the present research confirms that, processing, transport and trade of European commercialized smoked salmon are safe concerning to the presence of anisakis larvae, despite the current complexity of the food chain based on salmon products.

In contrast, the presence of Anisakis simplex larvae in wild smoked salmon confirms the cosmopolitan diffusion of this zoonotic species and the general assumption of a more negligible risk for the presence of zoonotic parasites in farmed fish products. Although all the parasites were found dead, their allergenic potential should

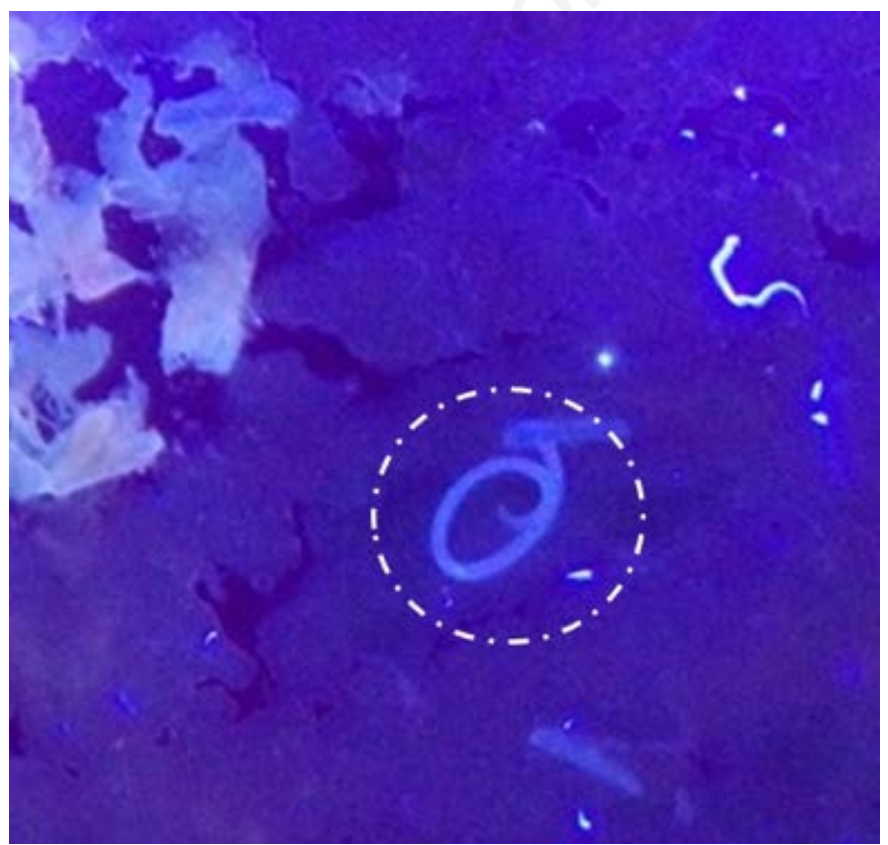

Figure 1. Single parasite detected under UV light examination in one of the smoked fillets of wild sockeye. Anisakis larvae is rounded with a white dotted circle. not be overlooked or underestimated in a risk analysis (Sánchez-Alonso et al., 2018). The possible derogation of freezing treatment for wild-salmon-derived products currently cannot be considered, based on data both from literature and data produced during this study.

The UV-press method used during the present survey, confirmed a sensitivity higher than visual inspection by candling provided by the current EU regulatory framework, since few larvae found in fillets had been missed by candling method. The standardization of this effective and feasible method could lead the industry to adopt it on large-scale for a self-assessed control system on Anisakis risk.

\section{Conclusions}

The present work represents the first comprehensive study on Anisakis risk in smoked products from farmed Atlantic salmon ever conducted in Europe. The results pointed out the absence of anisakid nematodes and therefore the negligible risk of anisakiasis linked to the consumption of smoked farmed Atlantic salmon products, while products from wild salmon still show a high risk for the presence of Anisakis larvae. As suggested by EFSA and EU Hygiene Package, for the other farmed fish species and relative fish products in EU, the pathway to assess the negligibility of zoonotic parasites risk should be similar to Atlantic salmon, contributing to improve the competitiveness of European aquaculture products in the global market.

\section{References}

Adams AM, Murrell KD, Cross, J. H. 1997. Parasites of fish and risks to public health. Rev Sci Tech Off Int Epiz 16:652-66.

Angot V, Brasseur P. 1993. European farmed Atlantic salmon (Salmo salar L.) are safe from anisakid larvae. Aquaculture 118:339-44.

Berland B. 1961. Nematodes from some Norwegian marine fishes. Sarsia 2:1-50.

Buchmann K, Mehrdana F. 2016. Effects of anisakid nematodes Anisakis simplex (s.1.), Pseudoterranova decipiens (s.1.) and Contracaecum osculatum (s.1.) on fish and consumer health. Food Waterborne Parasitol 4:13-22.

Chai JY, Murrell DK, Lymbery AJ. 2005. Int J Parasitol 35:1233-54.

Crotta M, Ferrari N, Guitian J. 2016. Qualitative risk assessment of introduc- 
tion of anisakid larvae in Atlantic salmon (Salmo salar) farms and commercialization of products infected with viable nematodes. Food Control 69:275-84.

D'Amelio S, Mathiopoulos KD, Brandonisio O, Lucarelli G, Doronzo F, Paggi L. 1999. Diagnosis of a case of gastric anisakidosis by PCR-based restriction fragment lenght polymorfism analysis. Parassitologia 41:591-3.

Deardorff TL, Kent ML. 1989. Prevalence of larval Anisakis simplex in pen-reared and wild-caught salmon (Salmonidae) from Puget Sound, Washington. J Wildl Dis 25:416-9.

Denstad AG, Lillevand M, Ulsund EA. 2015. Production planning and sales allocation in the salmon farming industry. Norwegian University of Science and Technology, Thesis.

EC Regulation No 2074/2005 of 5 December 2005 laying down implementing measures for certain products under EC Regulation No 853/2004 of the European Parliament and of the Council and for the organisation of official controls under EC Regulation No 854/2004 of the European Parliament and of the Council and EC Regulation No $882 / 2004$ of the European Parliament and of the Council, derogating from EC Regulation No 852/2004 of the European Parliament and of the Council and amending EC Regulations No 853/2004 and EC No 854/2004.

EFSA. 2010. Scientific Opinion on risk assessment of parasites in fishery products. Panel on Biological Hazards (BIOHAZ). EFSA J 8:1543.

FAO. 2018. The State of World Fisheries and Aquaculture 2018. Meeting the sus- tainable developement goals. Rome: FAO.

Karl H, Leinemann M. 1993. A fast and quantitative detection method for nematodes in fish fillets and fishery product. Arch Lebensmittelhyg 44:124-5.

Karl H, Baumann F, Ostermeyer U, Kuhn T, Klimpel S. 2011. Anisakis simplex (s.s.) larvae in wild Alaska salmon: no indication of post-mortem migration from viscera into flesh. Dis Aquat Organ 94:201-9.

Kijewska A, Rokicki J, Sitko J, Wegrzyn G. 2002. Ascaridoidea: A simple DNA assay for identification of 11 species infecting marine and freshwater fish, mammals and fish-eating birds. Experiment Parasitol 101:35-9.

Kleter GA, Prandini A, Filippi L, Marvin HJP. 2009. Identification of potentially emerging food safety issues by analysis of reports published by the European Community's Rapid Alert System for Food and Feed (RASFF) during a fouryear period. Food Chem Toxicol 47:932-50.

Levsen A, Maage A. 2016. Absence of parasitic nematodes in farmed, harvest quality Atlantic salmon (Salmo salar) in Norway - Results from a large scale survey. Food Control 68:25-9.

López I, Pardo MA. 2010. Evaluation of a real-time polymerase chain reaction (PCR) assay for detection of Anisakis simplex parasite as a food-borne allergen source in seafood products. J Agricult Food Chem 10:1469-77.

Lunestad BT. 2003. Absence of nematodes in farmed Atlantic salmon (Salmo salar L.) in Norway. J Food Prot 66:122-4.

MarineHarvest 2018. Salmon industry handbook. pp. 113.
Mo TA, Gahr A, Hansen H, Hoel E, Oaland Ø., Poppe TT. 2014. Presence of Anisakis simplex (Rudolphi, 1809 det. Krabbe, 1878) and Hysterothylacium aduncum (Rudolphi, 1802) (Nematoda; Anisakidae) in runts of farmed Atlantic salmon, Salmo salar L. J Fish Dis 37:135-40.

Noguera P, Collins C, Bruno D, Pert C, Turnbull A, McIntosh A, Cook P. 2009. Red vent syndrome in wild Atlantic salmon Salmo salar in Scotland is associated with Anisakis simplex sensu stricto (Nematoda: Anisakidae). Dis Aquat Org 87:199-215.

Sánchez-Alonso I, Carballeda-Sangiao N, González-Muñoz M, Navas A, Arcos SC, Mendizábal A, Careche M. 2018. Pathogenic potential of Anisakis L3 after freezing in domestic freezers. Food Control 84:61-9.

Wootten R, Yoon GH, Bron JE. 2009. A Survey of Anisakid Nematodes in Scottish Farmed Atlantic Salmon. Available from:

Wootten R, Yoon GH, Bron JE. 2010. A Survey of Anisakid Nematodes in Scottish Wild Atlantic Salmon. Available from: https://www.food. gov.uk/sites/default/files/media/document/722-1-1224_S14008_ext2_ final_Apr_10.pdf

Zhu XQ, Podolska M, Liu JS, Yu HQ, Chen $\mathrm{HH}$, Lin ZX, Luo CB, Song HQ, Lin RQ. 2007. Identification of anisakid nematodes with zoonotic potential from Europe and China by single-strand conformation polymorphism analysis of nuclear ribosomal DNA. Parasitology Res 101:1073-7. 